RESEÑA

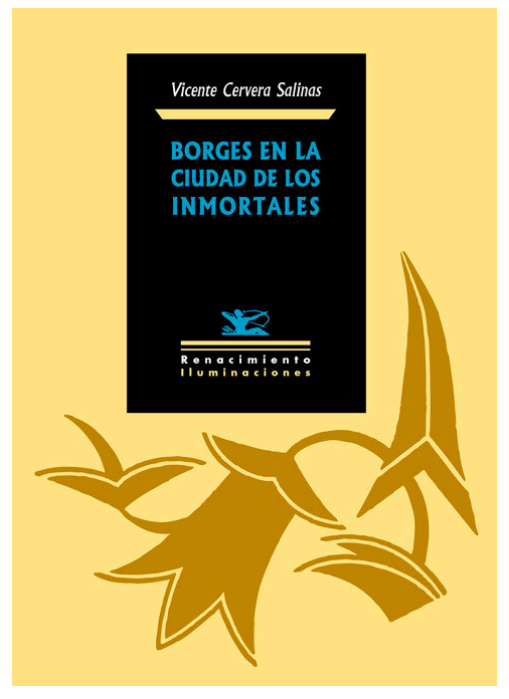

\title{
BORGES EN LA CIUDAD DE LOS INMORTALES
}

\author{
Vicente Cervera Salinas \\ Sevilla: Renacimiento, 2014 \\ 351 páginas
}

\author{
Por MARIO AZNAR PÉrEZ, UNIVERSIDAD \\ COMPLUTENSE DE MADRID \\ marioazn@ucm.es
}

Habrá quien piense que sobre la obra y la figura de Jorge Luis Borges está todo escrito. El mismo Borges ficcionalizó esta posibilidad en relatos tan celebrados como "La biblioteca de Babel". También jugó con la hipótesis panteísta de que todos los autores son un mismo autor, de que el escritor puede confundirse con la literatura, de que "la casi infinita literatura estaba en un hombre": un hombre inmortal.

Sin embargo, Vicente Cervera Salinas (Albacete, 1961), esgrimiendo su larga y sólida experiencia como docente y poeta, demuestra con este libro que seguir indagando el universo literario de Borges es, más que posible, necesario. Esta lectura crítica implica la aceptación de una contradicción que está a la altura de cualquier sucesión tautológica de hexágonos ad infinitum: la escritura de Borges es también la escritura sobre Borges, de modo que ésta no agota su literatura. En su riguroso compendio de estudios borgeanos, Vicente Cervera Salinas plantea un recorrido que no renuncia a ninguna de las facetas de la obra del escritor argentino, pues el análisis de su obra poética, narrativa y ensayística discurre intercalado a lo largo de los once capítulos que componen el volumen. Además, el libro consta de un prólogo memorable y un último capítulo a modo de epílogo, que, como un oráculo benefactor, nos anuncia: "A Borges lo volveremos a encontrar en cada vuelta del camino. Aunque hayamos querido olvidarlo" (349).

De este modo, ahuyentando a los fantasmas de la redundancia y del simple parafraseo, el autor propone un conjunto de ensayos literarios del más alto nivel académico, aunque la forma limpia y elegante de su prosa, y el carácter heterogéneo de los textos, abran las puertas a una lectura no sólo erudita y especializada, sino también placentera para cualquier persona 
interesada en la obra del hacedor porteńo. La rigurosidad de las interpretaciones y el completo aparato crítico y bibliográfico utilizado por Vicente Cervera Salinas, hacen de su obra un libro de referencia tanto en el campo de la literatura hispanoamericana en general, como en el del particular universo literario de Borges.

Al mismo tiempo, un sentido creativo de la labor crítica, una visión integral de la cultura y una lectura interdisciplinar que no se olvida de la filosofía ni de la historiografía cultural, aseguran, como se anuncia con justicia en el prólogo, "un nuevo y diverso acercamiento al poeta del porteño fervor y del elogio de la sombra" (9). Un acercamiento cuya estructura y contenido trataremos de sintetizar muy brevemente.

El capítulo primero (13-46), que da título al libro, presenta un exhaustivo estudio del relato "El inmortal", prestando especial atención a conceptos tan relevantes para entender el texto como son los de autor y narrador, de cuya dialéctica meta-textual Cervera Salinas extrae interesantes e inéditas conclusiones. Además, la reinterpretación del mito de la inmortalidad es sometida aquí a una lectura compleja e iluminadora, destacando la interdependencia de este tema - tan central en la literatura de Borges- con otros igualmente relevantes como son la identidad, el tiempo o el conocimiento; sin olvidar la original apreciación crítica acerca del motivo de la anamnesis o reminiscencia platónica.

En "Borges, lector del oriente fabuloso" (47-67), el autor plantea un interesante recorrido a través de los distintos ensayos que el escritor argentino dedicó, en su labor infatigable de comparatista de la traducción, a las múltiples versiones traducidas de textos clásicos como la Odisea o Las Mil y una noches. A partir de esta lectura panorámica, Cervera Salinas recompone la concepción borgeana de la traducción, entendida como un amplio proceso de "creacióntraducción" que transgrede las fronteras comunicativas del lenguaje de la creación literaria.

El tercer capítulo, "Borges y el logos divino: Juan I, 14" (67-107), está dedicado al comentario preciso y apasionado de los dos poemas en los que Borges trató el versículo de Juan al que se refiere el título, que ambas composiciones comparten: "Juan I, 14".

En "Jorge Luis Borges o la respiración de la inteligencia" (108-131), el autor no sólo reivindica la importancia del género ensayístico en Borges, sino que apela al dios Jano como símbolo de una poética bifurcada -"la ficción y el raciocinio" (109) - que en la obra del escritor argentino cobra forma perfecta e indivisible. Así, tras diseñar un breve mapa histórico del ensayo clásico y moderno, Cervera Salinas explicita las implicaciones que la escritura más estrictamente ensayística de Borges tiene sobre la composición de su universo literario y defiende que "el ensayo, respiración natural de la inteligencia, fue en su obra la vía para la aparición del hecho estético" (130).

"La poesía de la cultura: La esfera de Pascal, otro motivo de Proteo" (132-163) continúa la línea de estudio abierta por el trabajo que lo precede, e indaga la influencia en la obra de Borges del conjunto de ensayos que el uruguayo José Enrique Rodó escribió a partir del referente mítico del antiguo dios del mar: Motivos de Proteo (1909). 
En "La sombra de Sarmiento en la poesía de Borges" (164-190), el autor indaga la progresiva vinculación del joven Borges con la tradición cultural y literaria argentina, representada por algunas "figuras emblemáticas del panteón familiar" (165), de entre las cuales destaca el escritor y político Domingo Faustino Sarmiento. Así, se comenta la presencia de Sarmiento en los tres poemarios juveniles de Borges: Fervor de Buenos Aires (1923), Luna de enfrente (1925) y Cuaderno de San Martín (1929), y se analiza el último de los poemas que escribió sobre Sarmiento, de título homónimo, incluido en El otro, el mismo (1964).

El capítulo titulado "Jano o la profética memoria de Borges" (191-213), dividido en tres apartados bien definidos, propone una aproximación al mito de Jano y un repaso de su presencia en la obra de Borges, quien, como señala el autor, supo explorar a fondo "las potencialidades icónicas y simbólicas del mito de Jano en su literatura y, en especial, en su obra poética".

Por su parte, en "Una lectura ontológica de Walt Whitman según Borges" (214-236), se estudia la presencia constante del poeta norteamericano en la obra poética y ensayística de Borges, desde "su descubrimiento del bardo norteamericano durante los ańos de su juventud europea" (214), hasta la conferencia que sobre él pronunció en la Universidad de Chicago en enero de 1968, pasando por la imprescindible traducción borgeana de Hojas de hierba y el "Prólogo" que la precede.

"Tres humanistas del siglo XX: Pedro Henríquez Ureńa, Alfonso Reyes y Jorge Luis Borges" (237-270) recorre los puntos de encuentro que conforman esa tríada privilegiada del humanismo hispanoamericano: "tres figuras eminentes, imbricadas en su base y hermanadas en su formación originaria" (268). En primer lugar se señalan y comentan los vínculos Ureńa-Reyes, para después estudiar la conjunción entre Henríquez Ureńa y Borges, y terminar tratando la confluencia de estas tres "almas literarias" (265).

En "El sur de Santayana a la luz de Borges" (271-319) se estudia la recepción del escritor y filósofo hispano-estadounidense George Santayana en el hispanismo y en la obra de Jorge Luis Borges, situando como punto de intersección la labor de Raimundo Lida como difusor del 'santayanismo' en Argentina.

"A los lectores de Sur" (320-342), último capítulo del volumen, plantea una interesante revisión general del papel que la revista Sur tuvo en el ámbito cultural argentino e hispanoamericano del siglo XX, prestando especial atención a su proyección contemporánea y cosmopolita, a los motivos -generalmente extraliterarios- que determinaron la progresiva decadencia de la publicación a partir de los años sesenta, y a la enérgica e inquieta figura de su fundadora, Victoria Ocampo.

El libro termina, como hemos señalado al principio, con el texto "Las horas y los siglos de Borges (a modo de epílogo)" (343-349), en donde se retoma el tema del primer ensayo -el cuento «El inmortal»- y se recogen los frutos del recorrido crítico que abarca los once capítulos.

Así, a sesenta y cinco años de la publicación de El Aleph, el libro Borges en la Ciudad de los Inmortales nos invita a releer la obra integral del autor argentino desde parámetros renovados, y a unirnos a Vicente Cervera Salinas en 
su descubrimiento del legado literario borgeano como algo siempre "nuevo e indescifrado". Y aunque habrá quien piense que sobre su obra y su figura está todo escrito, hay libros como éste desde donde Borges sigue escribiendo, escribiéndose y escribiéndonos. 